\title{
Specialty preferences of final year students studying physical therapy in Peshawar
}

\author{
Shehermaan Shadab Amin ${ }^{1}$, Shagufta Jabeen ${ }^{2}, K_{\text {Kanwal Gul }}^{3}$, Zainab Malishba Ahmed ${ }^{4}$, Abdul Salam ${ }^{5}$, Huma Balqias $^{6}$, Madiha Anees ${ }^{7}$
}

\section{Submitted: \\ April 6, 2020 \\ Accepted: \\ May 11, 2020}

\section{Author Information}

${ }^{1-7}$ Rehman College of Rehabilitation Sciences

\begin{abstract}
Introduction: Choosing a specialty after graduation plays an important role in the life of a student. However, little is known about students' preferences about selection of specialties in physical therapy students in developing countries. This study aimed to find out specialties' preferences and factors that influence students' choices of selection any specialty in physical therapy students studying in final year. Material \& Methods: This cross-sectional study was conducted on students of physical therapy institutes located in Peshawar, Khyber Pakhtunkhwa. The study was carried out from November 2018 to April 2019. Data was collected from final year students only. All students who were eligible, were included for this survey and a total of 185 students participated in this survey. Written informed consent was obtained from all participants and questionnaires were distributed amongst them. The data collection tool used for this study was a semi-structured questionnaire. SPSS version 22 was used for data analysis. The measure of frequencies was obtained for variables and chi-square test was applied to measure the association between variables

Results: A total of 185 students, 101 (54.6\%) female and 84 (45.4\%) male with a mean age of $23.44 \pm 1.54$ years participated in this study. Among all the participants, 145 (78.3\%) intended to specialize in the future. The most preferred specialty amongst these participants was Musculoskeletal Physical Therapy ( $n=80,43.2 \%)$. The least chosen specialty was Geriatrics Physical Therapy ( $n=2,1.1 \%$ ). Among male participants no one selected Gynecological Physical Therapy as specialty. Prestige within the profession was considered the most important factor for specialty preference $(n=118,81.4 \%)$.

Conclusion: Musculoskeletal Physical Therapy remained preferred choice of specialty amongst students of final year studying Doctor of Physical Therapy in Peshawar, Khyber Pakhtunkhwa. The most important reported factor effecting specialty preferences amongst physical therapy students is prestige within the profession.
\end{abstract}

Key Words: Perception, Physical Therapy, Specialty

The authors declared no conflict of interest and agreed to be accountable for all aspects of the work in ensuring that questions related to the accuracy or integrity of any part of the work are appropriately investigated and resolved.All authors contributed substantially to the planning of research, questionnaire design, data collection, data analysis and write-up of the article as part of a student research team at Rehman College of Rehabilitation Sciences.

The research work was supervised by Dr. Madiha Anees (PT) Assistant Professor Rehman College of Rehabilitation Sciences

This article may be cited as: Amin SS, Jabeen S, Gul K, Ahmed ZM, Salam A, Balqias H, Anees M. Specialty preferences of final year students studying physical therapy in Peshawar. Rehman J Health Sci. 2020;2(1).6-9

\section{INTRODUCTION}

In the entire life of a student, selection of a career specialty is one of the most important thing. Specialties differ in many aspects such as mode of performing duties, professional interests, workload and skills. Normally, information from different sources are gathered to make a decision about a specialty selection. ${ }^{1}$ The selection of a specialty by post graduate students plays an important role in the health care system. It has been reported that career counselling is one of the major contributing factors in specialty selection amongst students. ${ }^{2}$ Knowledge about specialties can be useful which helps undergraduates students to set their priorities and future goals for which they have been struggling. ${ }^{3,4}$ With the passage of time, new advancements are becoming integral parts of medical field that leads to an increased demand of professionals who are specialized in their field of practice. ${ }^{5}$ There are variety of choices in choosing a specialty for students learning medical education, however, many young health care practitioners cannot decide the area they want to specialize in due to the lack of knowledge about the field. ${ }^{6}$ During past years, physical therapy has emerged as a profession in health care system which intends to provide beneficial services to patients and to the community. ${ }^{7,8}$ In 1985, specialization in clinical physical therapy began which flourished with the passage of time due to varying needs of the society. ${ }^{9}$ After the commencement of five years Doctor of Physical therapy program, physical therapy as a profession stands independent in its practice pattern. ${ }^{3}$ Consistency has been required in order to become a specialized clinical physical therapist for the maintenance of which, residency and fellowship programs have emerged to provide more advanced knowledge and skills in the specialized area. American Physical Therapy Association had developed 'the description of specialty practice' used as a guide for the residency program which involves the whole spectrum of expert practices for certain specialty area. ${ }^{10}$ After graduation when students select a specialty their choices are affected by some past experiences which they had during their 
course of study. This might include interaction with other members, patients and different health care professionals. ${ }^{10,}{ }^{11}$ The specialties offered in Physical Therapy by different universities are Musculoskeletal Physical Therapy, Neurological Physical Therapy, Cardiopulmonary Physical Therapy, Sports Physical Therapy and some others. ${ }^{12}$

Different factors influence identification of chosen specialty by Physical Therapy students. Some of these factors are intrinsic like those related to personal preferences and attributes, while some are extrinsic factors related to the particular environment in which one works and spends time in. The factors which have impact on specialty preference are the students' personal interest, pressure of fellow students, self-inspiration, financial status and quality life styles. ${ }^{6,13,14}$ Furthermore, other factors like students' academic record, personality traits, working hours and expected salary from the desirable field have also a strong influence on the specialty choice. ${ }^{15-17}$ According to research studies, selection of a specialty by students is most of the time affected by the way they want their lifestyle to be in future for which they first think about a good income. ${ }^{18,19}$ Another study concluded that some other elements help in selection of career including income from that career, the personality of a student and gender. ${ }^{20}$ There was many genderbased differences related to specialty choice which include family traditions, norms, values and expectations. ${ }^{21}$ It was suggested that female students consider working hour and nature of work more while males consider challenging field, salary, future advancements in the field and personal life during choosing specialty. ${ }^{22,23}$ As Physical Therapy is an emerging profession, its advances in the education are still limited due to many reasons. Students are not aware of the choices regarding the specialties in the profession being offered which might be due to the limited specialties offered by universities. Therefore, the current study aimed to develop an understanding of perceptions regarding physical therapy specialties and investigating the influence of determinants which affect the specialty choice. This might help in future planning for some of the students along with policy makers. Moreover, it might be helpful in career counselling for undergraduates as most of them seem confused about their future plan for specialty selection. In addition, this study might help in providing information regarding some specialties which are not very well known to the students. The objectives of the study were to explore the specialty preferences of final year DPT students of Peshawar and to find out the factors which influence the choices of students in specialty preference.

\section{MATERIALS \& METHODS}

This cross-sectional study was conducted on the students of five physical therapy institutes of Peshawar, Khyber Pakhtunkhwa which included including Rehman College of Rehabilitation Sciences (RCRS), Institute of Physical Medicine and Rehabilitation (IPMR), Northwest Institute of Health Sciences (NWIHS), Mehboob Medical Institute (MMI) and NCS University System. The duration of the study was six months from November 2018 to April 2019. Only final years physical therapy students were included. Census sampling was performed, and a total of 185 participants were selected. All students' participation in this study was entirely on volunteer basis. After approval of research proposal from graduate committee, permission was obtained from head of physical therapy institutes i.e., RCRS, IPMR, NWIHS, MMI and NCS University System. Students meeting inclusion criteria were invited for participation and purposes of the study were explained to all the students and inform consents were obtained from all willing participants. Questionnaires were distributed and explained to each participant. The data collection tool used in this study was semi-structured questionnaire of closed ended questions which explored the preferred specialty of the students and the factors which influence their choices. SPSS version 22 was used to analyze the data. The measure of frequencies was obtained for variables and chi square test was applied to measure the association among the categorical variables. Data was analyzed descriptively using frequency distribution and graphically presented using chart. Gender, marital status, institution and preferred post graduate place were considered as variables.

\section{RESULTS}

A total of 185 students were recruited for this study, among which $101(54.6 \%)$ were females and $84(45.4 \%)$ were males. The mean age of the participants was $23.44 \pm 1.54$ years (mean \pm s.d). Out of the total, 170 (91.9\%) students were single, 4 (2.2\%) were engaged and 11 (5.9\%) were married. Most of the students 71 (38.3\%) were from Institute of Physical Medicine and Rehabilitation, followed by NCS University System ( $\mathrm{n}=43,23.2 \%)$, Mehboob Medical Institute $(n=30,16.2 \%)$, Rehman College of Rehabilitation Sciences $(n=26$, $14.0 \%)$ and Northwest Institute of Health Sciences $(n=15,8.1 \%)$ (Table 1).

Table 1: Demographics detail of the participants

\begin{tabular}{|l|l|l|}
\hline Variables & & \multicolumn{1}{|c|}{ Frequency } \\
\hline Gender & Male & $84(45.4 \%)$ \\
\hline & Female & $101(54.6 \%)$ \\
\hline Age & mean \pm s.d & $23.44 \pm 1.5459$ \\
\hline Institutes & RCRS & $26(14.1 \%)$ \\
\hline & IPMR & $71(38.4 \%)$ \\
\hline & MMI & $30(16.2 \%)$ \\
\hline & NCS & $43(23.2 \%)$ \\
\hline Marital Status & Single & $15(8.1 \%)$ \\
\hline & Married & $11(5.9 \%)$ \\
\hline & Engaged & $4(2.2 \%)$ \\
\hline
\end{tabular}


Out of 185 participants, 145 (78.3\%) students had decided to specialize after their DPT degree, a small number $(n=16,8.6 \%)$ was not interested to specialize and $24(12.9 \%)$ were not sure about their decision.

Among students who decided to specialize after DPT program, Musculoskeletal Physical Therapy was the most preferred specialty $(\mathrm{n}=80,43.2 \%)$, followed by sports Physical Therapy $(\mathrm{N}=21,11.4 \%)$. Geriatrics Physical Therapy was the least selected specialty $(n=2$, $1.1 \%$ ) among the included participants (Table 2).

\begin{tabular}{|l|l|} 
Table 2: Specialties Preference of The Participants \\
\hline Specialty & Frequency \\
\hline Musculoskeletal Physical Therapy & $80(43.2 \%)$ \\
\hline Neurological Physical Therapy & $16(8.6 \%)$ \\
\hline Cardiopulmonary Physical Therapy & $14(7.6 \%)$ \\
\hline Sports Physical Therapy & $21(11.4 \%)$ \\
\hline Pediatrics Physical Therapy & $8(4.3 \%)$ \\
\hline Gynecological Physical Therapy & $4(2.2 \%)$ \\
\hline Geriatrics Physical Therapy & $2(1.1 \%)$ \\
\hline
\end{tabular}

There was a positive association $(p=0.04)$ found between gender and the chosen specialty. Most preferred specialty among both male and female participants was Musculoskeletal Physical Therapy with a frequency of $34(23.5 \%)$ and $46(31.7 \%)$ respectively. Male students after Musculoskeletal Physical Therapy chose Sports Physical Therapy 16 (24.2\%) while females' second priority was Cardiopulmonary Physical Therapy with frequency of 10 (6.9\%). Furthermore, male participants did not choose Gynecological Physical Therapy $0(0 \%)$ as their preferred specialty while only $1(0.7 \%)$ male and $1(0.7 \%)$ female participants chose Geriatrics physical therapy as a preferred specialty (Table 3 ).

Table 3: Gender Association With Specialities

\begin{tabular}{|c|c|c|c|}
\hline Specialty & Males & Females & p-Value \\
\hline Musculoskeletal PT & $34(23.5 \%)$ & $46(31.7 \%)$ & \multirow{8}{*}{0.04} \\
\hline Neurological PT & $8(5.5 \%)$ & $8(5.5 \%)$ & \\
\hline Cardiopulmonary PT & $4(2.8 \%)$ & $10(6.9 \%)$ & \\
\hline Sports PT & $16(11 \%)$ & $5(3.4 \%)$ & \\
\hline Pediatrics PT & $3(2.1 \%)$ & $5(3.4 \%)$ & \\
\hline Gynecological PT & $0(0.0 \%)$ & $4(2.8 \%)$ & \\
\hline Geriatrics PT & $1(0.7 \%)$ & $1(0.7 \%)$ & \\
\hline Total & $66(45.5 \%)$ & $79(54.5)$ & \\
\hline
\end{tabular}

There was a positive association between institution and preferred specialty $(\mathrm{p}=0.01)$. Students of RCRS $(\mathrm{n}=12,60.0 \%)$, IPMR $(\mathrm{n}=29$, 56.9), NWIHS $(n=6,54.5 \%)$ and NCS University System $(n=21$, $56.7 \%$ ) preferred MSK Physical Therapy, while students of MMI chose Sports physical therapy $(n=9,34.6 \%)$ their first preferred specialty.
Among the 145 students who had decided a specialty, 98 (67.5\%) students wanted to continue their studies and specialize abroad because of quality education ( $n=59,60.2 \%)$, wide range of specialties offer $(n=24,24.4 \%)$ and higher income $(n=15,15.3 \%)$ while those who wanted to continue within country were 47 (32.4\%) (Figure. 1).

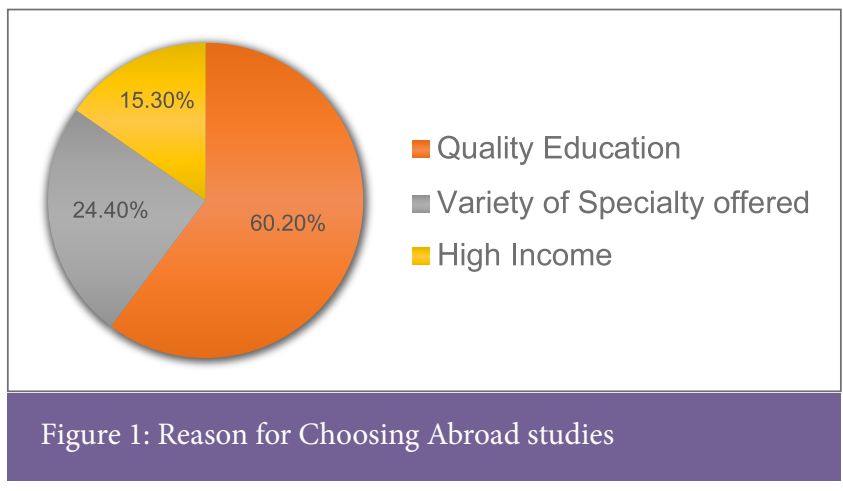

Closed ended questions were used to find out the factors which influence the choices of students, among which "prestige within profession" was considered as the most influential factor $(n=118$, $81.4 \%$ ) for specialty selection. While 'specialties that classmates or friends choose' was the least chosen factor $(n=32,22.1 \%)$ (Table 4).

\begin{tabular}{|l|c|c|}
\hline \multicolumn{1}{|c|}{ Table 4: Factors Influencing Specialty Choice } & Yes & No \\
\hline Factors & $113(77.9 \%)$ & $32(22.1 \%)$ \\
\hline Challenging diagnostic problems & $117(80.7 \%)$ & $22(19.3 \%)$ \\
\hline $\begin{array}{l}\text { Specific interest in patient } \\
\text { population seen }\end{array}$ & $100(69 \%)$ & $45(31.0 \%)$ \\
\hline Good Income & $83(57.2 \%)$ & $62(42.8 \%)$ \\
\hline Flexible working hours & $80(55.2 \%)$ & $65(44.8 \%)$ \\
\hline Advice from mentor & $118(81.4 \%)$ & $27(18.6 \%)$ \\
\hline Prestige within profession & $54(37.2 \%)$ & $91(62.8 \%)$ \\
\hline Lack of overcrowding in field & $55(37.9 \%)$ & $90(62.1 \%)$ \\
\hline Advice from parents & $112(77.2 \%)$ & $33(22.8 \%)$ \\
\hline Clinical rotation experience & $115(80 \%)$ & $29(20 \%)$ \\
\hline $\begin{array}{l}\text { Your strengths in subjects related } \\
\text { to a specialty }\end{array}$ & $32(22.1 \%)$ & $112(77.2 \%)$ \\
\hline $\begin{array}{l}\text { Specialties that classmates or } \\
\text { friends choose }\end{array}$ & $95(65.5 \%)$ & $50(34.5 \%)$ \\
\hline Research opportunities & $118(81.4 \%)$ & $45(31.0 \%)$ \\
\hline A specialty that is rapidly advancing & $100(69 \%)$ & $45(31.0 \%)$ \\
\hline Multiple job opportunities & & \\
\hline
\end{tabular}

No association was found between age and the factors upon which students decided their specialty $(\mathrm{p}=0.91)$. Intention of respondents to specialize in future did not shown any association with gender $(\mathrm{p}=0.73)$, institution $(\mathrm{p}=0.51)$ and marital status $(\mathrm{p}=0.34)$.

\section{DISCUSSION}

The aim of this study was to identify specialties which is most preferred by students in Peshawar. A similar study conducted in Karachi had indicated that $51.7 \%$ students were more interested in doing specialization from within the country which is contrary to our results. Findings of this survey showed that $67.5 \%$ students were interested in doing specialization from abroad. The difference might be due to the higher exposure of different specialties in 
hospital setups which provide knowledge and clinical practice of chosen field. ${ }^{24}$

Regarding the preferred specialty, a study carried out in Islamabad demonstrated that the most preferred specialty among Physical Therapy students was Musculoskeletal Physical Therapy (40.0\%) which is in accordance to the current study suggesting that the included participants preferred Musculoskeletal Physical Therapy $(43.2 \%)$ as their chosen specialty. The similarity in the results is due to the advancements in the field of musculoskeletal physical therapy and also most of the clients in Physical Therapy clinics of Pakistan present with musculoskeletal problems. ${ }^{12}$

On the other hand, a study demonstrated that the least preferred specialties by male students was cardiopulmonary physical therapy (7.5\%) and by females was sports physical therapy (8.9\%). In contrast to our study, the least chosen specialty by male and female students was gynecological physical therapy $(0.7 \%)$ and geriatrics physical therapy $(0.7 \%)$. The economic factor and future income prediction were considered as the factors which affect the choices of students. ${ }^{12}$ In a similar study conducted in Turkey, it was found that the reasons for choosing a specialty were good income and prestige which are reflected in the results of current study as well. Findings of this survey suggested that prestige within the profession (81.4\%) is the most frequently reported factor in choosing specific specialty. The results of these studies suggested that the thought of future lifestyle and greater financial income helps in the decision making while choosing a specialty. ${ }^{25}$

A study conducted on junior doctors found that the least chosen factor for specialty preference was advice from parents or family member $(16.1 \%)$. While in our study, chosen specialty of peers $(22.1 \%)$ was suggested as a least chosen factor. The reason behind these results may be due to the advancements in the field of health system which made the students to understand the area of interest better and encourages them to choose a preferred specialty by the prestige and value of particular field rather than taking advices from others. ${ }^{26}$

\section{CONCLUSION}

This study concluded that both male and female respondents chose Musculoskeletal Physical Therapy as their first preferred specialty choice. Males did not prefer to specialize in gynecological physical therapy and females did not intend to specialize in geriatrics physical therapy. Majority of respondents wanted to continue their studies out of the country. This study suggested that students had related their specialty choices to prestige within profession and advancement of the field as the major contributing factors in choosing specific specialty.

\section{RECOMMENDATIONS}

The policies of educational system should be formulated in a way that encourage students to pursue their careers within their own country. Career counseling shall be done in the medical institutions and students shall be given confidence for selecting field of their choice. The study helps to understand the fact that the choice of physical therapy specialties and location of practice is multidimensional and multifactorial. There is a need to aware the students, parents, universities and the government regarding the necessity of available and required fields.

\section{LIMITATIONS}

Data collection was limited to final year students only which might be one of the limitations of this study. Moreover, data collection tool was semi-structured questionnaire which was not validated.

\section{REFERENCES}

1. Weissman $\mathrm{C}$, Tandeter $\mathrm{H}$, Zisk-Rony RY, Weiss YG, Elchalal U, Avidan A, et al. Israeli medical students' perceptions of six key medical specialties. Israel journal of health policy research. 2013; 2:19.

2. Mehmood SI, Kumar A, Al-Binali A, Borleffs JC. Specialty preferences: trends and perceptions among Saudi undergraduate medical students. Medical teacher. 2012; 34:S51-S60.

3. KhaderY, Al-Zoubi D, Amarin Z, Alkafagei A, Khasawneh M, Burgan S, et al. Factors affecting medical students in formulating their specialty preferences in Jordan. BMC medical Education. 2008; 8:32.

4. Draper C, Louw G. What is medicine and what is a doctor? Medical students' perceptions and expectations of their academic and professional career. Medical teacher. 2007; 29:e100-e7.

5. Ahmad OB, Lopez AD, Inoue M. The decline in child mortality: a reappraisal. Bulletin of the World Health Organization. 2000; 78:1175-91.

6. Shahab F, Hussain H, Inayat A, Shahab A. Attitudes of medical students towards their career-perspective from KhyberPukhtunkhwa. Medicine. 2013;36:27.

7. Avgerinos ED, Msaouel P, Koussidis GA, Keramaris NC, Bessas Z, Gourgoulianis K. Greek medical students' career choices indicate strong tendency towards specialization and training abroad. Health Policy. 2006; 79:101-6.

8. Avidan A, Weissman C, Elchalal U, Tandeter H, Zisk-Rony RY. Medical specialty selection criteria of Israeli medical students early in their clinical experience: subgroups. Israel journal of health policy research. 2018; 7:20.

9. Milidonis MK, Godges JJ, Jensen GM. Nature of clinical practice for specialists in orthopaedic physical therapy. Journal of
Orthopaedic \& Sports Physical Therapy. 1999; 29:240-7.

10. Jensen GM, Gwyer J, Shepard KF, Hack LM. Expert practice in physical therapy. Physical therapy. 2000;80:28-43.

11. Saigal P, Takemura Y, Nishiue T, Fetters MD. Factors considered by medical students when formulating their specialty preferences in Japan: findings from a qualitative study. BMC Medical Education. 2007; 7:31.

12. Akram L, Malik AN, Siddiqi FA, Amjad I. The preferred academic and clinical specialty of final year student of Physical Therapy. Rawal Medical Journal. 2013;38:301-4.

13. Abdulghani HM, Al-Shaikh G, Alhujayri AK, Alohaideb NS, Alsaeed HA, Alshohayeb IS, et al. What determines the selection of undergraduate medical students to the specialty of their future careers? Medical teacher. 2013; 35:S25-S30.

14. Ossai EN, Uwakwe KA, Anyanwagu UC Ibiok NC, Azuogu BN, Ekeke N. Specialty preferences among final year medical students in medical schools of southeast Nigeria: need for career guidance. BMC medical education. 2016; 16:259.

15. Roupret M, Hupertan V, Chartier-Kastler E. The choice of a medical career in a population of 600 second-cycle French medical students preparing the nationalranking exam. Presse medicale (Paris, France: 1983). 2005; 34:786-90.

16. Arnold MW, Patterson AF, Tang AL. Has implementation of the 80 -hour work week made a career in surgery more appealing to medical students? The American journal of surgery. 2005; 189:129-33.

17. Ibrahim M, Fanshawe A, Patel V, Goswami K Chilvers G, Ting $M$, et al. What factors influence British medical students' career intentions? Medical teacher. 2014; 36:1064 72.
18. Dorsey ER, Jarjoura D, Rutecki GW. Influence of controllable lifestyle on recent trends in specialty choice by US medical students. Jama. 2003; 290:1173-8.

19. Gelfand DV, Podnos YD, Wilson SE, Cooke J, Williams RA. Choosing general surgery: insights into career choices of current medical students. Archives of Surgery. 2002; 137:941-7.

20. Pianosi K, Bethune C, Hurley KF. Medical student career choice: a qualitative study of fourth-year medical students at Memorial University, Newfoundland. CMAJ open. 2016; 4:E147.

21. Alers $M$, van Leerdam L, Dielissen P, LagroJanssen A. Gendered specialities during medical education: a literature review. Perspectives on medical education. 2014; 3:163-78.

22. Lefevre JH, Roupret M, Kerneis S, Karila L. Career choices of medical students: a national survey of 1780 students. Medical education. 2010; 44:603-12.

23. Buddeberg-Fischer B, Klaghofer R, Abel T, Buddeberg $\mathbf{C}$. The influence of gender and personality traits on the career planning of Swiss medical students. Swiss Medical Weekly. 2003; 133:535-40.

24. Huda N, Yousuf S. Career preference of final year medical students of Ziauddin Medical University. Educ Health (Abingdon). 2006; 19:345-53.

25. Fevzi Dikici M,Yaris F,Topsever P, Muge Filiz T, Serdar Gurel F, Cubukcu M, et al. Factors affecting choice of specialty among firstyear medical students of four universities in different regions of Turkey. Croatian medical journal. 2008; 49:415-20.

26. Jabeen A, Ashraf S, Mahmood T, Shah SA, Riaz F. Specialty Preference and the Factors Affecting it among the Junior Doctors of Wah Medical College. 